\title{
Design Research on Electronic Learning Products Based on "People-oriented"
}

\author{
Zhiliang Xia \\ Wenzhou Vocational \& Technical College, wenzhou 325035 \\ Xia441@sina.com
}

\begin{abstract}
This paper makes research on the form of electronic learning products based on Ergonomics. The design idea of "people-oriented" is fully reflected through the design of electronic learning products on product semantics, modeling, touching texure and interactive interface, etc. And under the function principle of products in use, pleasantness is added to products on operating mode, physiology, psychology and product semantics, which makes electronic information products more pleasant, and reflects the development direction of electronic information products' external form.
\end{abstract}

Keywords: Electronic learning product, people-oriented, form; design

\section{Introduction}

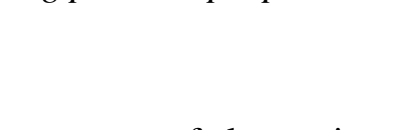

China is a big manufacturing country of electronic products. According to the data released by Ministry of Industry and Information Technology, from January to July of 2013, China's electronic information products kepta relatively rapid growth in export and import, the total amount of which reached to 757 billion USD, with a growth of $19.3 \%$. The growth rate occupied $32.2 \%$ of national foreign trade amount, $10.8 \%$ higher than that of national goods' foreign trade amount, of which the export amount was 440.2 billion USD, occupying $35.5 \%$ of national foreign trade export amount, with a growth of $17.0 \%, 13.3 \%$ higher than the growth rate of the same period last year and $7.5 \%$ higher than that of national foreign trade export, and the import amount was 316.8 billion USD, occupying $28.5 \%$ of national foreign trade import amount, with a growth of $22.6 \%, 24.1 \%$ higher than the growth rate of the same period last yearand $15.3 \%$ higher than that of national foreign trade import. The growth trend is obvious. However, China is not a power of electronic information products, especially in the form design and manufacturing of electronic learning products. Electronic learning product is such precision equipment as integrates various high technologies like mechanical power, electronic information transmission and computer micro programming, etc, so the relatively complex operation of such equipments and many interference factors like radiation, vibration and terrible interface design make the flexible, accurate and long-time operation uneasy and may easily result in tension and fatigue of users, thus causing zero-improvement of efficiency. In addition, along with the continuous development of science and technology, the electronic information equipments are focusing more on science and technology, pleasantness, delicacy and comfort, etc. Therefore, in the form design of electronic learning products, to change problems existed in previous external form design such as monotonous 
color, inappropriate collocation, stiff lines and unpleasant texture and to design out products with innovative form, pleasant color, appropriate layout, beautiful lines, exquisite details and high aesthetic value, at the same time with visual and psychological sensation of comfort in the process of operation become a breakthrough that can create substantial improvements within a short time for Chinese electronic learning products' form design [1, 2]. "People-oriented" educational products are developed through the product innovation to meet the needs of the times. The analysis model is shown in Figure 1.

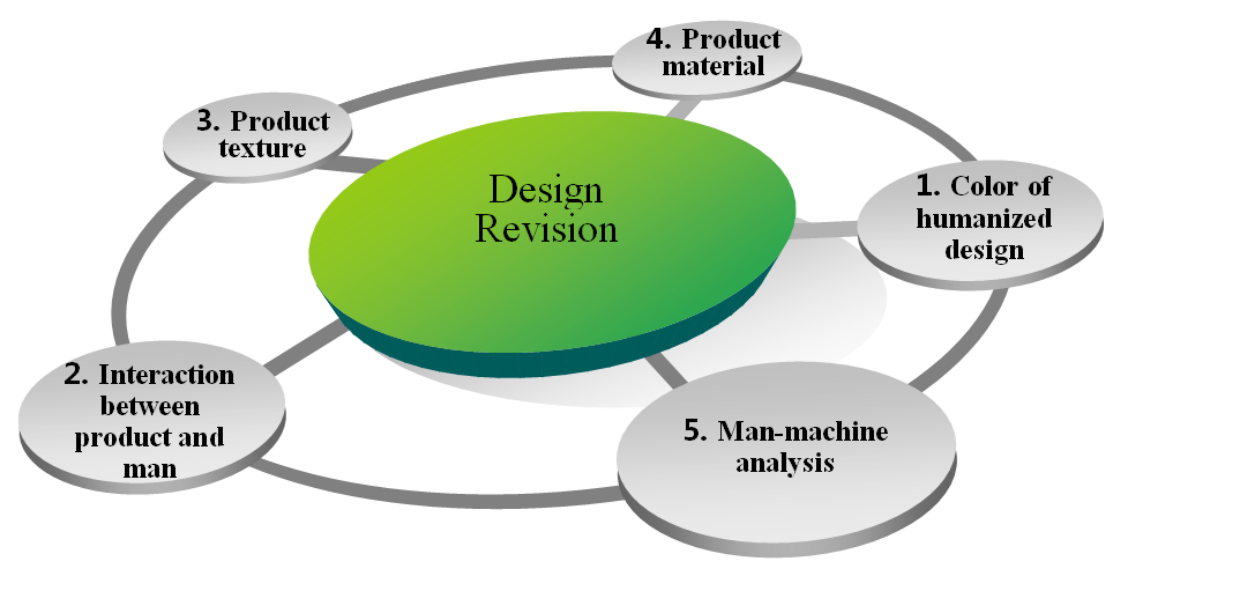

Figure 1. Development drawing of "people-oriented" educational products

\section{The Implication of Humanized Design}

To put it simple, humanized design refers to "people-oriented" design, namely, on the basis of people's essentian requirements, meeting people's needs on products' use function and aesthetic funct on through the comprehensive design in products' external technology and art, and expressing a spirit of humahistic concern $[3,4]$. The design concept includes focusing on and respecting human's thought, and it stresses that respecting people should be the foundation of business operation, which requires designers when designing products, in conformity with the rdea of "people-oriented", to experience, excavate and summarize the psychological densation and desire of mass consumers, to explore the rules of design and consumers'psychological activities which facilitates the integration of emotion and reason in design, thus improving the humanized effect of design, motivating the consumers' purchasing of products, and earning profit for enterprises.

\section{Pleasant Design Contents of Electronic Learning Products' Forms}

Humanized electronic learning products design should not only meet consumers' needs psychologically, physiologically and intelligently, but also meet the ecology of products' cost and materials commercially. And its connotation is mainly reflected through the following aspects: 
Emotional design: Product design is adapt to consumers' subjective experience and inner feeling, and meets people's emotional needs by virtue of products' appearance such as color, shape, structure and text, so as to improve the psychological aesthetics of consumers.

Personalized design: It refers to that product design meets consumers' needs on different ages, genders and status on the basis of meeting human's general physiological, psychological and intelligent needs. In modern society, needs for personalized products are becoming increasingly strong.

Cost design: It refers to a design thinking of focusing on products' cost accounting and reducing the burden of consumers. Due to the "excessive packaging" aroused in society, merchants tend to pack the ordinary products over-delicately without consideration of additional economic burden brought to consumers which may result to unnecessary economic waste.

Ecological design: It's also called sustainable design, that is, reusable and re-circulated product design is encouraged to use in order to save materian tesources and to reduce waste. For instance, recycled materials and containers such as, bottles and pots can be used and the destruction of them should be convenient on the basis of meeting ecological needs without damaging the environment.

"People-oriented" design focuses more on research of color, modeling, material texture and operation interface. In addition, the effect of man-maichine interaction is also emphasized in design, which should mainly take the following aspects into consideration.

\subsection{Color factor}

Color, as the principal visual aesthetic celement, greatly influences people's visual perception and reflects people's psychologieal emotion. Carolyn Bloom, a famous art psychologist of America, has ever said that, "Color arouses various emotions, expresses feelings, and even influences our norma physical sensations." Thus it can be seen that the application of color has become an indportant linguistic form of designers. The color and form of products are inseparable and complementary, and color can be transmitted to human brain through optic herve, not onty arousing subjective sensations such as temperature, weight, distance and hardness, butalso connecting to the previous memory and experience, producing association, and developing a series of emotional responses by color, as shown in Table 1.

Table 1. Moral and association of colors

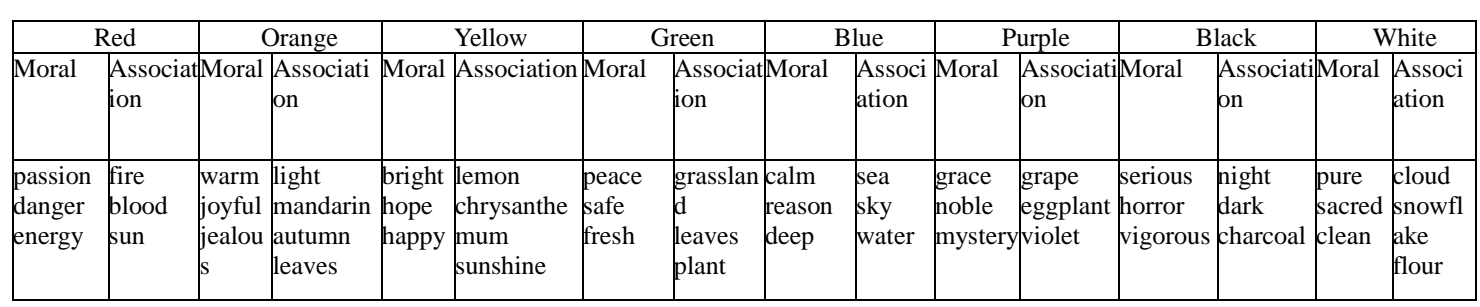

The previous electronic learning products' colors were often dark blue-oriented, with deep and dull tone, and even some products were not painted, giving people a feeling of somberness, obsolescence and lifelessness. While modern life requires the electronic learning products' color not only to be beautiful, decent, coordinate and gentle, but also to meet the requirements of products' functions, operation environment and people's aesthetic needs. The market research and analysis on melody colors can be shown in Table 2. 


\section{Table 2. Color analysis on electronic learning products}

\subsection{Modeling factor}

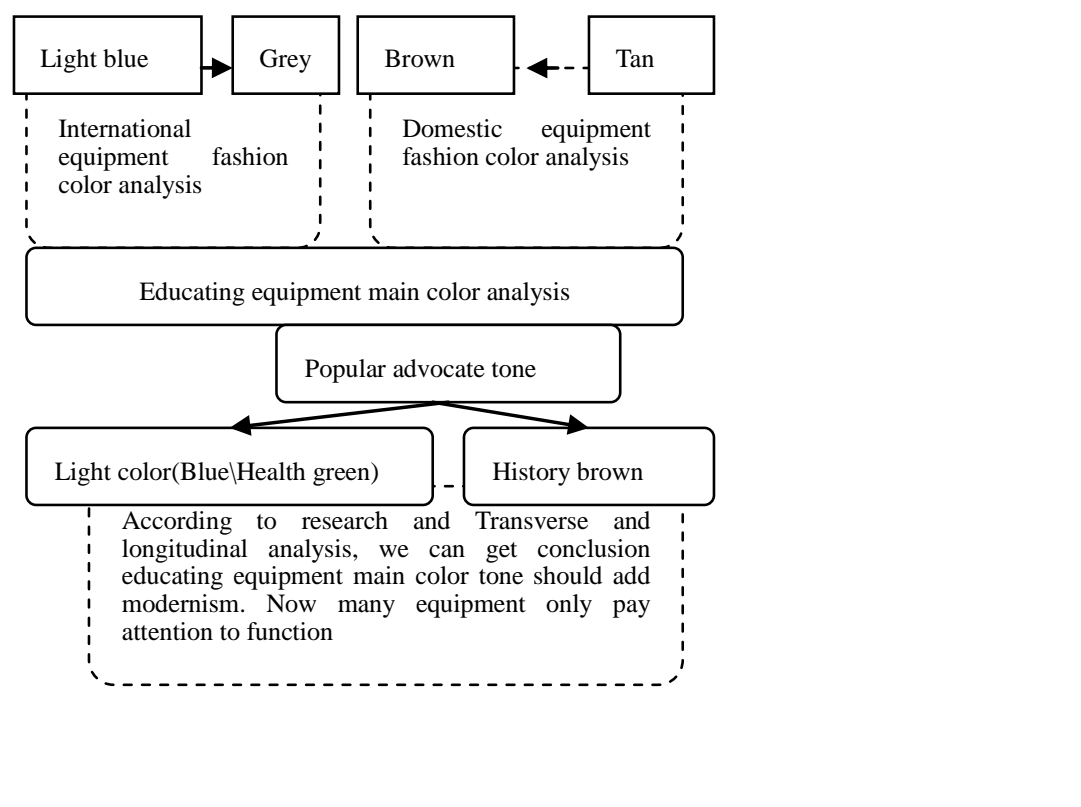

Modeling is the external performance of object, and an important factor of information exchange between object and humah. The reason why the basic modeling of object is the mainline of information communication is that the object's modeling not only expresses the shape, but more than "shape" on intension and extension. "Shape", the reflection and embodiment of objective law, is materialized, real or hard, while the "form" of modeling is spiritual and vital. That is to say, turn the modeling language of products into emotions, attach them with implications, and produe pleasant emotional experience for consumers.

Modeling is mainly shown though the form of product constituted by shape, surface and lines with differen characteristics which form the morphological styles or morphological characteristics on the whote The existing special equipments of electronic information often have rigid shape, dull lines, unbalanced design, messy details, unnatural transition, as well as monotonous lines and surfaces, which results in lacking of vitality. Therefore, in designing appearance, on the basis of meeting its basic functions, the aesthetic principle of modeling for electronic learning products shall be taken into consideration, and the coordination between unity and variation, proportion and dimension, stabilization and lightness, pace and rhythm, as well as contrast and conciliation shall be handled well $[5,6]$. By weighing deliberately the component elements of shape, surface and lines in design, morphological characteristics with visual comfort and unified features should be combined together; and on this basis, a harmonious relation reflecting the characteristic and requirement of the times should be created through conciseness, texture, unity and associated perception.

\subsection{Material texture}

The modern product packaging has become various in material and texture. As with humanization, it mainly refers to the relation between human and ecological environment, the reflection of protecting environment, the application of ecological materials and the texture suitable for consumers' psychological and physiological sensations. For example, product materials can be used repeatedly and renewably; glass bottles applied by beer and beverages can be used repeatedly; waste can be recycled and reproduced. What's more, such 
environmental protection materials as are edible and degradable can not only reduce wastage and pollution, but also can avoid the damage to human by poisonous, harmful and radioactive contamination. Texture is a three-dimensional detail of product's packaging, namely the concave-convex, polishing and sand blasting on the material's surface. The application of texture shall be adapt to the consumers' psychology, environment, behavior, thought and desire, etc. For example, the design of bath \& skin care products' packaging bottles applies carved texture of concave-convex on the surface, which not only produces a feeling of water and waves, but also prevents falling when taking a bath. Apple Inc, a well-known U.S. computer manufacturer, designed and produced iMacG3 Series computer, as is shown in Figure 2. The gorgeous and multicolored transparent plastic shell texture design not only changes people's cold, indifferent intention on electronic learning products, but also greatly reflects the personalized model and feature of products, which conveys a strong demand for pleasantness on association and yearning, and brings the enterprise great conmercial benefits.

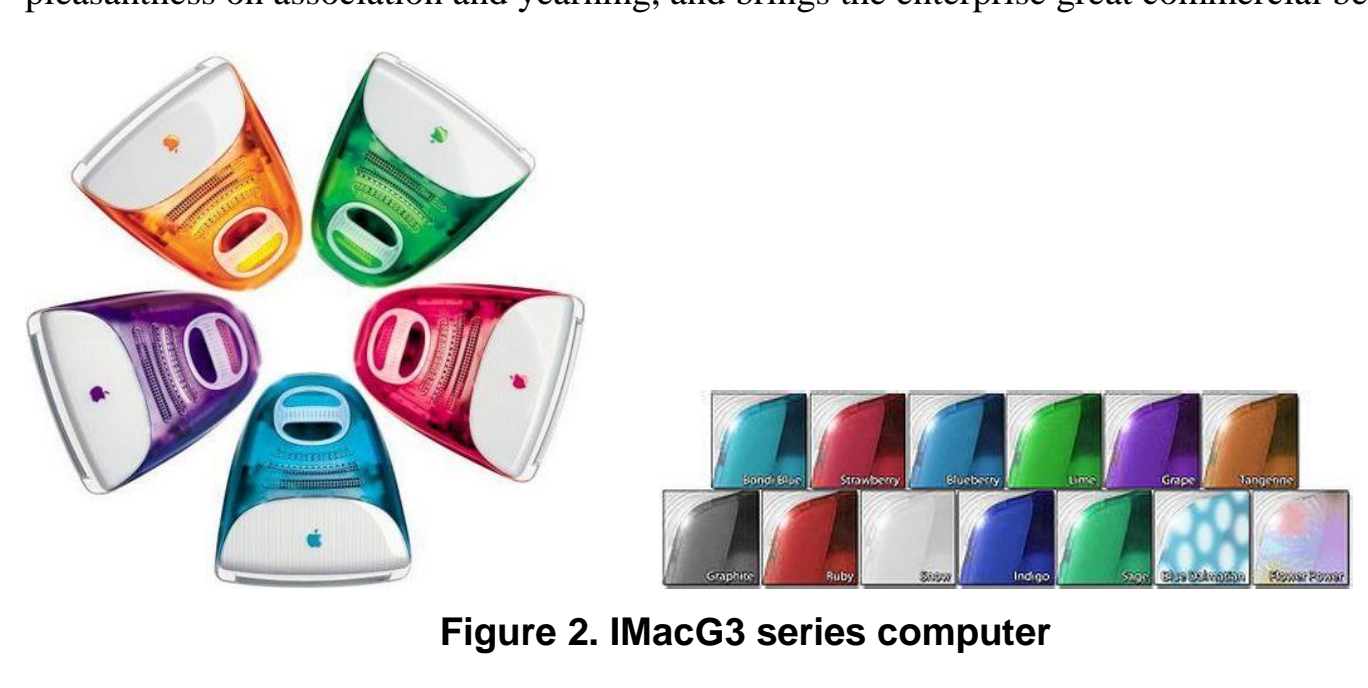

Materials of electronic learning products are mostly artificial materials, which is widely applied in practice. It is because even though the corresponding natural materials can give the product more natural qualities, their own weaknesses are rather obvious: the limited structural strength, processing feasibility, corrosion resistance, poor durability, a limited number of resources, and so fortb. The development and application of artificial materials greatly make up such defects; at the same time bring about a revolution about performance and concept, endowing external morphologic expression of electronic products with richer and more exaggerated attributes and a strong modern atmosphere. For example, grinding metal surfaces and advanced fiber products as well as smooth engineering plastics pass out all the time the technological sense integrating artificial processing and modernization.

\subsection{Operation interface}

Operation interface here mainly refers to man-machine interface. Man-machine interface, the medium of transferring and exchanging information between man and machine, is a crossover study field covering computer science and psychology, art design, cognitive science and ergonomics. HMI (Human-Machine interface), is the medium of transmitting information between man and machine, namely a communication interface between man and machine. The complex signal structure of the electronic learning products makes its operation interface relatively cumbersome. Disordered layout predisposes irritability, making people feel shoddy. What's more, there may be real security risks. 
3.4.1. Principle of usability: Operation panel is the primary interface of man-machine Interaction, where detailed information controlling operation can be conducted by human. Its position, inclination angle, the display and the size and location of control unit, etc should all make people under a comfortable, accurate and efficient working condition in observation and operation. The operation panel's position and shape can be varied, generally including fitting type, suspending type, extended type, and separation type according to the relative position with body. Operation panel should be positioned in accordance with the modeling of the device and personnel's specific operating requirements. For example, the instrument panel should adopt dark tones with no stimulation and reflections; pointer's color should have a clear distinction with the that of dial so as to enhance the contrast between the two, and be coordinate as far as possible with the color of tick marks in order to improve recognition accuracy, to enhance the sense of order of panel's match color, and to rich the color effect of panel. The size selection of hand wheel and crank in manipulators is closely linked to their use purpose and use method. Figure 3 lists the appropriate rotation radius of hand wheer and crank under different application characteristics, and the size of joystick's handling part. This, a reasonable man-machine interface makes electronic learning products elegant $\backslash$ in the fornt, easy to understand, simple to operate and have a guide function, which allows the operator to feel pleasant and happy, so as to improve the work efficiency.

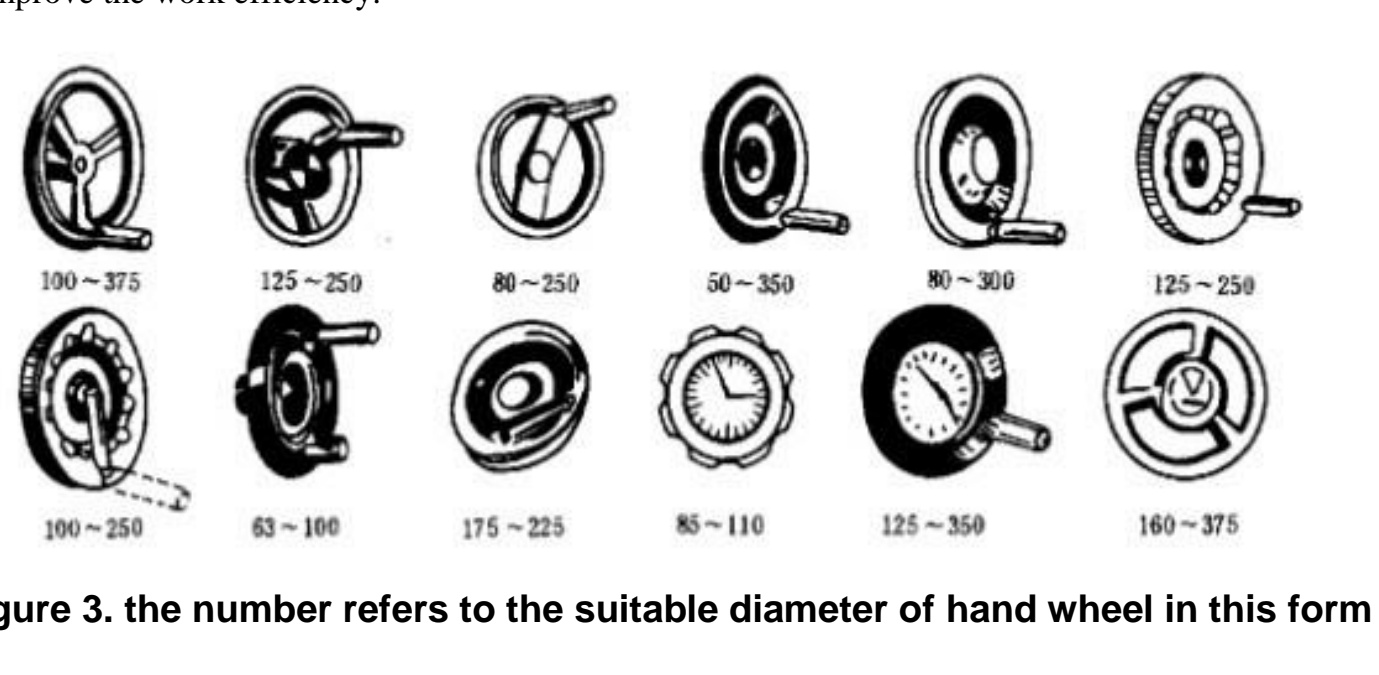

3.4.2 Dynamic principle: This principle means keeping the operation idea integrating space and time into mind. The loading of eddcational electronic information equipments should never be satisfied with two-dimensional flat spaoe or three-dimensional space, should have information conversion in more aspects such as time and space to convert more of information, and should focus more on information exchange and updating in the operation and design of educational electronic technology equipments, namely designing the surface of products in an attitude of keeping pace with the times. An important design difference between educational electronic technology equipments' surfaces and two-dimensional plane lies in the difference between two-dimension and three-dimension[7,8].. The bearing forms of graphic design are only limited to the two-dimensional book cover, advertising leaflets or brochures with slightly richer contents, but relatively speaking, educational electronic technology equipments are varied and changing, the design concept of which is not to confined to the surface control of operation menu only, but to apply man-machine interactive interface, thus fully meeting the users' requirements in all aspects.

3.4.3 Principle of consistency: It refers to the law of unity and harmony. In designing, states presented by four surfaces should not only have differences but also be integrated in one environment, and effect, emotions, circumstances and sound should be integral and unified. In the design of educational electronic technology equipments, the harmony and unity of style shall be kept on the surface: color or texture, even places that need to be highlighted through differences should maintain unified on style in all aspects. Many factors can be applied by us in the design, but special attentions should also be paid. 
We should have an universal consciousness, which can be finally born in specific form. This form not only carries the consciousness of national culture and requirements of the times, but also reflects the psychology aesthetic appeal of human.

\section{Man-machine analysis}

According to the "people-oriented" design concept of educational products, products are analyzed in posture of standing, sitting, and alternative posture of standing-sitting, in order to increase the comfort, controllability and space rationality of teaching aids' control panel and seat height, optimize the interaction between products and human, so as to keep the operator's body comfortable and stable at work and make accurate control and operation. Each part of the structure of control panel should not have backlog, cutters, and controls that may wound people; seats are generally not equipped with handrails, otherwise the security of operators must be guaranteed with handrails [9]. And the innovation of educational products should be enhanced. The man-machine analysis model of educational products is shown in Table 3.

Table 3. Model sheet of man-machine analysis of educational products

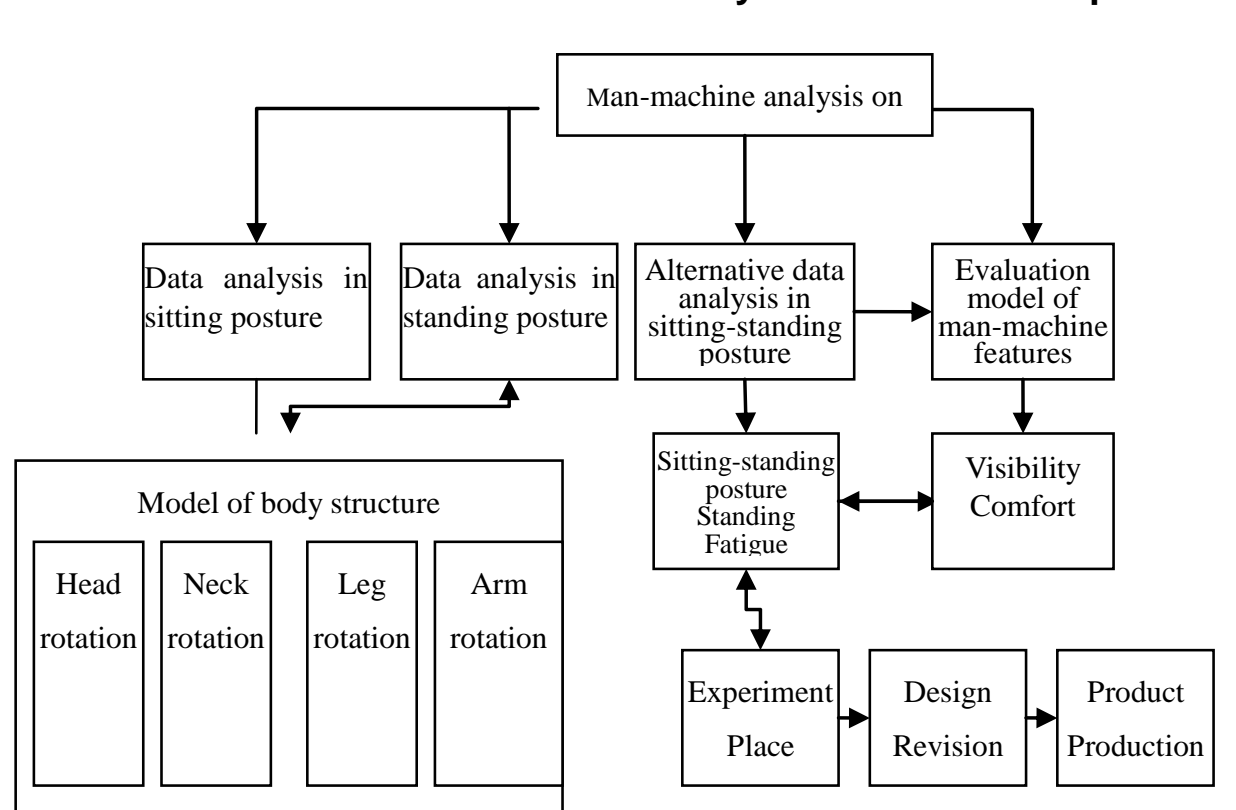

\subsection{Sitting vew shed analysis on visible teaching aid}

According to GB / T 13547-1992 Human dimensions in workspaces, GB / T 15759-1995 body template design and use requirements, and GB10000-88 Human dimensions of Chinese adults, as eyes in sitting posture can rotate around 26 degrees to the largest, the operation buttons such as the commonly used switch should be placed in the best area within the view shed, and the dead zone in sitting posture should be put less or no operation buttons. For reference drawing of partial data analysis, see Figure 4. 


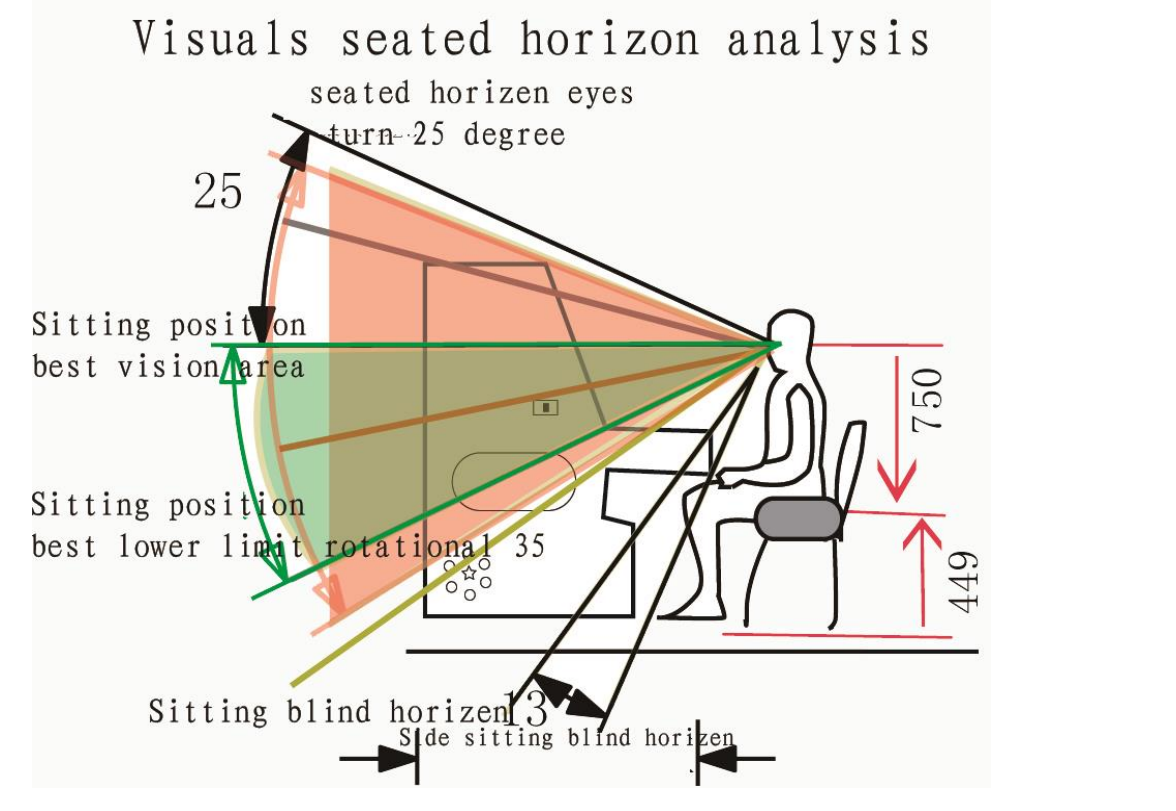

Figure 4. Reference diavwing of partial data analysis

\subsection{Standing view shed analysis}

In applying teaching apparattus or equipments used in standing posture, the main operating handle or placed objects should be within the best operating area for arms in order to avoid time wasting and energy wasting brought by walking back and forth. For those operating floors or placed objects out of the view shed area, the operating floors should be adjusted lower or placed inclined yithin the area of view shed in order to facilitate the operation. The reference drawing of partial data analysis on teaching aids is shown in Figure 5.

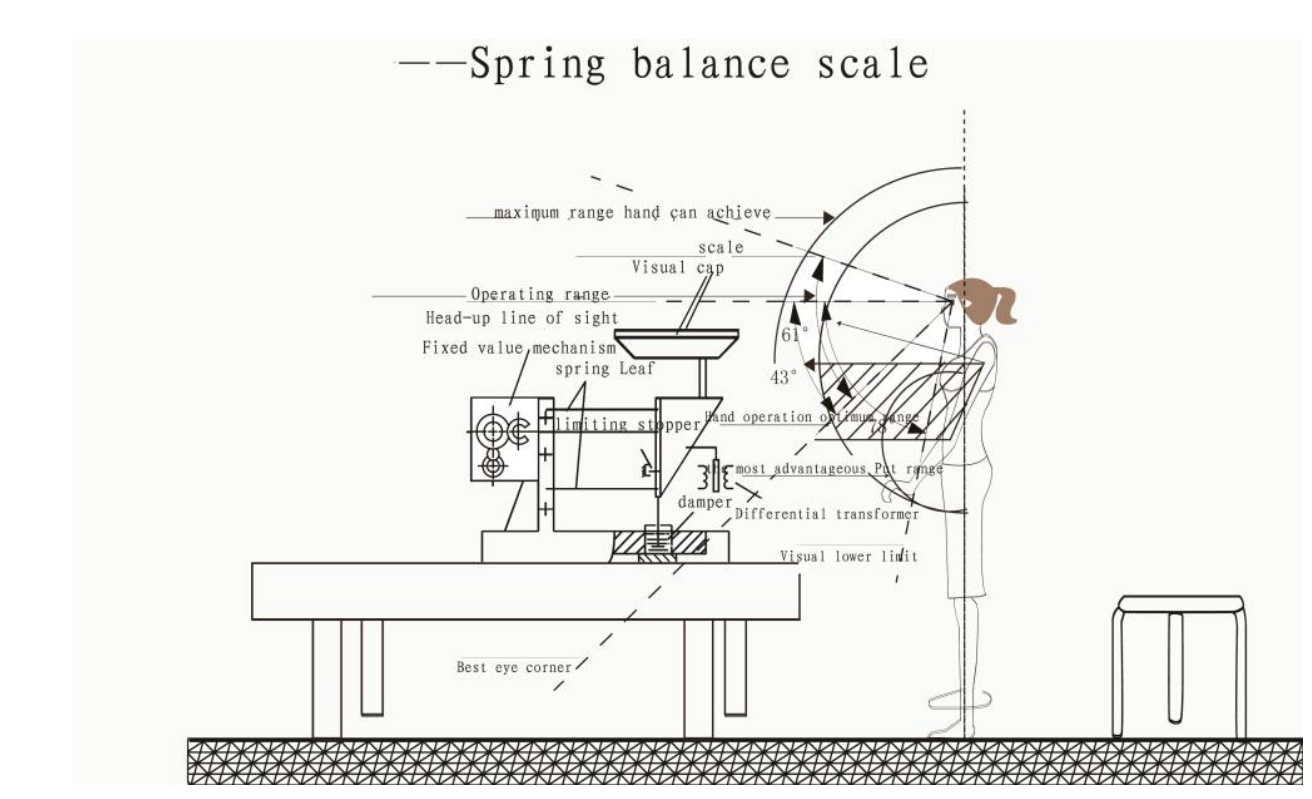

Figure 5. Partial data analysis on educational equipment 


\subsection{Alternate analysis on standing-sitting posture}

In analyzing work plane of standing-sitting posture, the heights of seats are applied differently according to the different teaching aids. Generally the height of the seat depends as far as possible on the height of standing posture in order to facilitate the alternation of standing and sitting. Based on the analysis on more than $90 \%$ human body models, $670-800$ is preferable for seats, and some teaching aids need to be provided with pedals for the rest of feet. And a 20-30 degree angle for pedals is provided in order to reduce fatigue, as is shown in Figure 6.

\section{Figure 6. Alternate analysis on partial data in standing-sitting posture}

According to the usage characteristics of educational equipments, it is the functions that determine the design methods either by sitting, standing, standing-sitting or otherwise. Through the man-machine,analysis and adjustment on view shed and operating range, etc, the humanization needs or educational equipments should be met. Figure 7 detailedly analyzes the seat height in the alternative state of standing and sitting posture. According to the human body model of men and women GB / T 14776-1993 Ergonomics, the size of operating post is preferably670-800mm, and the design principle should be: comfortable in alternation of sitting and standing; seats are handled with skid resistance to prevent seat movement during operation. Because of the long-time standing before the work bench, and in order to alleviate the stran of the leg muscles, a foot pedal with a height range of $300 \mathrm{~mm}-380 \mathrm{~mm}$ need to be added at the bottom; and a slope with an angle range of 120-135 degrees need to be added at the bevel of pedal and vertical plane $[10,11]$. By increasing pedals and inclination of pedals, the legs and feet are placed comfortably; the force bearing points of legs are allocated in different places; two legs tread alternately in accordance with the need to reduce the strain degree of muscles on legs and feet. According to the characteristics of packaging aids, the height of the platform to the ground is controlled as $1000-1100 \mathrm{~mm}$, and the control key of operating platform is placed at the position of $300-350 \mathrm{~mm}$ distance on platform. 


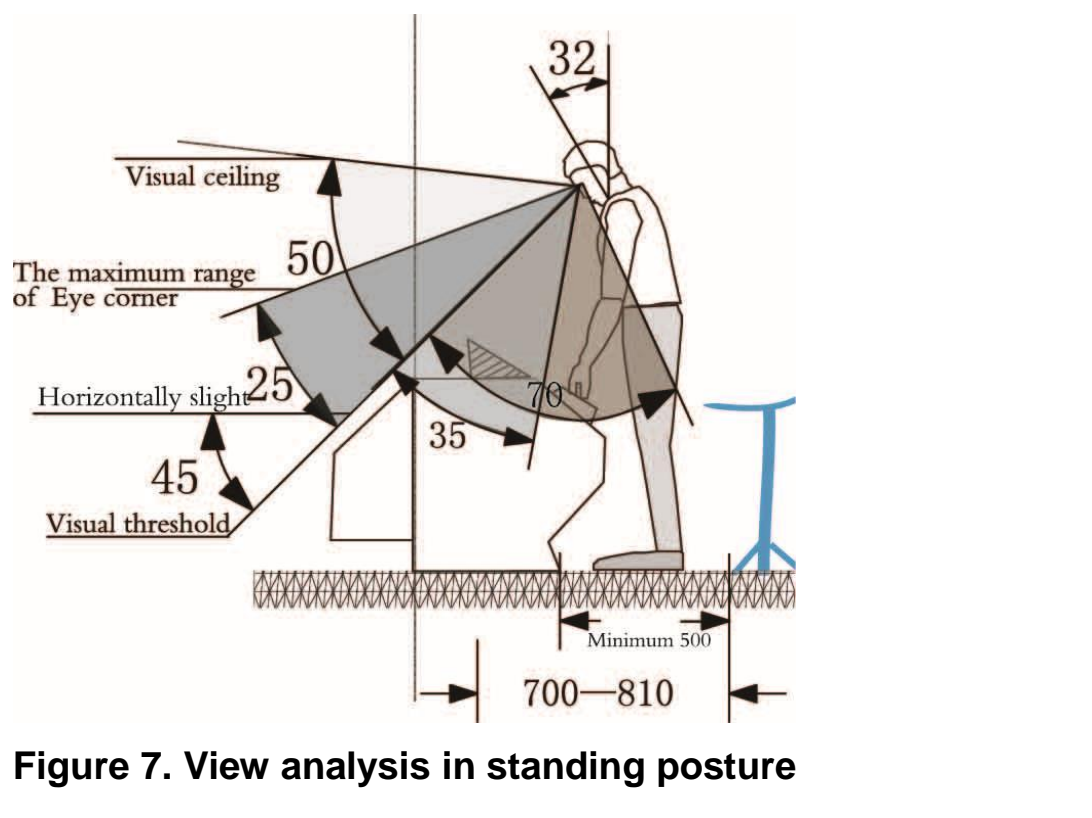

Make analysis on standing posture of 95 percent of humanbody model: the included angle of lowering head and rising head is 30 degrees; the angle between operation surface of electronic educational and visual upper lipit is 50 degrees; the visible angle to one's back below the operation surface is 70 degrees; The optrimum vertical angle to the operation surface when bowing is 60 degrees; the minimum distance from seat to the bottom of operation floor is $500 \mathrm{~mm}$; and the size from seat to the rear operation floor is controlled as $700-810 \mathrm{~mm}$. If the designed operating handle for operation floor in standing posture is out of operable range, designers need to improve, the position and the height of the operating handle to meet the needs. Operation analysis in standing posture is shown in Figure 7.

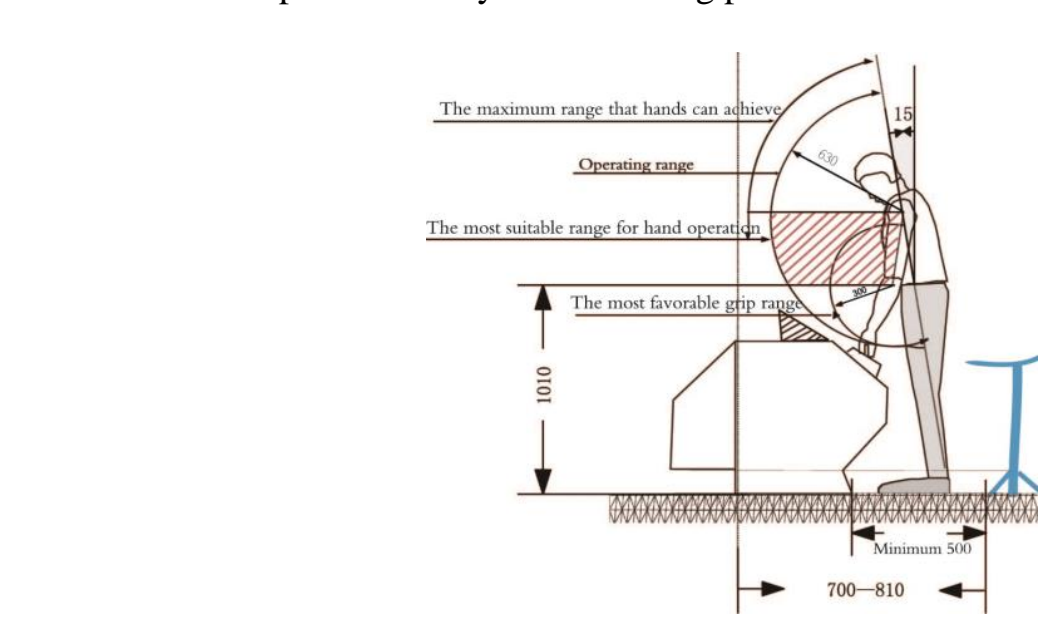

Figure 8. Operation analysis in standing posture

According to GB / T 15759-1995human body model design and use requirements, the movement characteristics of human upper limb in man-machine contacts and interactions, as well as the relational model of upper limb's static and dynamic movement direction within the surface, the rotatable diameter from the center of the palm to shoulder of entire arm is about $6300 \mathrm{~mm}$; the rotation diameter of elbow is about $3000 \mathrm{~mm}$; and the included angle 
with body's center of gravity when bowing is 15 degrees. The control button cannot be placed within the maximum diameter range that hands can reach to. If it is placed to the maximum diameter, it will not be the optimum ergonomic angle. The hand control should be placed in the most appropriate range and the optimum angle. Small button should be placed in the most favorable gripping range. Operation analysis in standing posture is shown in Figure8.

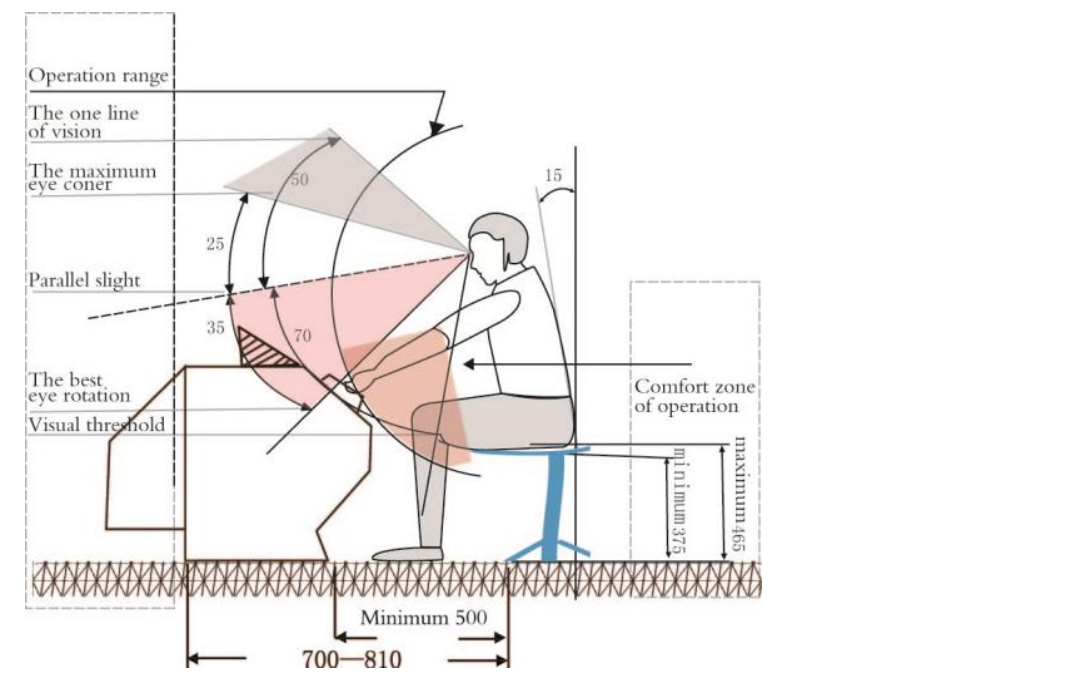

Figure 9. View analysis in sitting posture

Make view analysis in sitting posture on 15 percent of human body models. When the curvature of spine is 15 degrees, the control button should be placed within the best operational range, so as to achieve the best comfort of body to play. Visual panel placed between the usual sight line and the fisible view angle, the minimum $500 \mathrm{~mm}$ distance from tables and chairs to ards, and 25 degroes angle between the maximum rotation angle of eyes and the horizonal sight line can keep the operator always in the optimal control state, and make observation any time anysthere on signals of the equipment, and the results indicated by various types of equipments instruments, visual panels, and promptly make reactions so as to reasonably complete a variety of operations. Through the analysis on parameters and improvement of products' panels, operators' fatigue from long time operation can be reduced. View analysis in sitting posture is shown in Figure 9.

\section{Conchusions}

In today's increasingly competitive market, consumers have been unsatisfied with the basic functions of products, and are yearning for product packaging to meet their physiological and psychological requirements as well as material and spiritual needs. Through the study on user-friendly product design factors and the specific implementation, more humanized, emotional and aesthetic connotations need to be added to product packaging design, in order to reflect the care for humanization, and to establish a harmonious and unified relationship between human and products, and between man and environment.

\section{Fund program}

2012 Teacher's professional development project of visiting scholars in institutions of higher education (FX2012125); Ministry of Education's subproject of the key project in the 
national educational science's Twelve-Five planning (DCA110195-11001);2011 Zhejiang planning project on educational technology research (JB078).

\section{References}

[1] D.Yulan, (Ed.), "Ergonomics (Revised edition)", Beijing Institute of Technology Press, Beijing, (2006).

[2] H.Renke, (Ed.), "The History of Industry Design", Beijing Institute of Technology Press, Beijing, (2000).

[3] L.Binbin, (Ed.), "Design Psychology", China Light Industry Press, Beijing, (2001).

[4] Z.Shuyong, Z.Yaqing and Q. Qinghua, "Brief talk on the pleasant design of wheel loader", Engineering machinery, vol. 12, no. 32, (2003).

[5] X. Zhiliang, Y. Zhenhe and L. Xin, "Humanized design of mechanical products in coal mine", engineeving, vol. 3, no. 75, (2008).

[6] C. Manru and Z. Dawei, "Study on the development mode of man-machine interface and its application analysis", engineering, vol. 4, no. 28, (2007).

[7] X. Zhiliang, (Ed.), "Package design", China Light Industry Press, Beijing, (2012).

[8] L. Chengpeng, "Using VBA to design curved surface based on LATIA softuare", Journal of Guizhou University: NaturalScience, vol. 4, no. 24, (2007).

[9] U. Jayaram and S. Jayaram, "Introducing quantitative analysis methods into yirtual environments for real-time and continuous ergonomic evaluations", Compuers in Industry, ‘ol. 3, no. 57, (2006).

[10] Y. Zhenhe and L. Xin, "Model Evaluation Based on Emotional Fúniture Industrial Design Elements", International Journal of Advancements in Computing Technology, vol. 4, no.22, (2012).

[11] R. Baoxiang, (Ed.), "The basic ergonomics and its applications”, China Machine Press, Beijing, (2007).
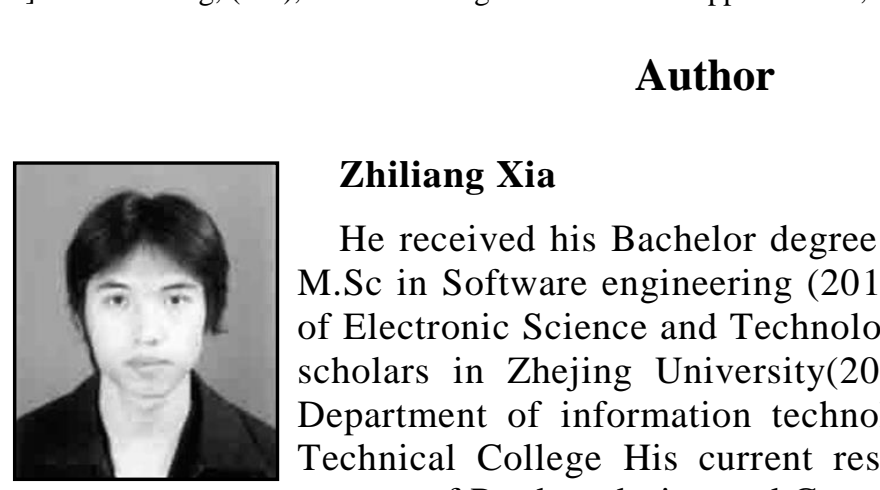

He received his Bähelor degree. in Industrial Design (2003) and M.Sc in Software engineering (2010) from University of University of Electronic Science and Technology of China. He was the Visiting scholars in Zhdjing University(2012-2013). Now he is lecturer at Department of information technology in Wenzhou Vocational \& Technical College His current research interests include different aspects of Product design and Computer aided design.

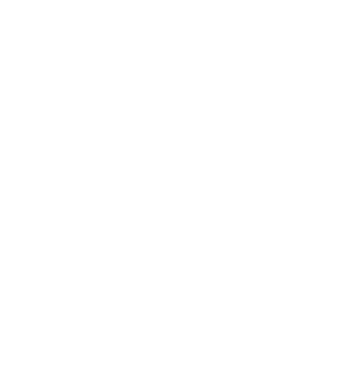

